\title{
Research on the Innovation of Teaching Methods in Colleges and Universities
}

\author{
Jovanny Luna \\ School of Business Administration, South China University of Technology, Guangzhou, China
}

How to cite this paper: Luna, J. (2017). Research on the Innovation of Teaching Methods in Colleges and Universities. The Educational Review, USA, 1 (2), 39-42. http://dx.doi.org/10.26855/er.2017.02.004

Corresponding author: Jovanny Luna, School of Business Administration, South China University of Technology, Guangzhou, China.

\begin{abstract}
Through the methods of literature and on-the-spot visit, this paper aims at studying the teaching system of physical education theory and the innovation of teaching methods in colleges and universities, and promoting the perfection of the teaching system of physical education (PE) theory in universities.
\end{abstract}

Keywords

College PE, Theoretical Teaching, Method Improvement

\section{Introduction}

With the development and progress of social economy, people's pursuit in health is stronger and stronger. Now, many sports clubs appear in the field of sports economy, playing an important role. The sports club can now be said to represent the new trend of the development of PE teaching mode (Zhu, 2008).

\section{Constructing the Teaching Theory System of PE Based on the Quality-Oriented Education}

The 21st century is an extremely competitive era, including economic competition, scientific and technological competition, talents competition, educational competition and so on. The theory of physical education should also strive to adapt itself to the requirements in the development of the times, to train more talented people for the society, and it is also a reform and development of physical education in schools. The outline of educational reform and development in China clearly stipulates that the physical education in school must be geared towards all students to improve students' comprehensive quality and promote their all-round development (Zhao \& Wang, 2011; Wang, 1998).

\subsection{Change of Ideas}

With the development of modern education in China, physical education also faces great challenges. According to modern educational thoughts, school education must closely contact with the educational activities of the future society, and it is no longer a pure school activity. Therefore, physical education should be the same. We should arouse students' active learning through PE, so that students' body and psychology can develop healthily to meet the needs of social development in future. We should organically integrate preschool sports, primary and secondary school sports, sports and social sports as a whole. From here we can see that, the school physical education concept has undergone a tremendous change. Through physical education, we can help students to form a good physical fitness.

\subsection{System Construction}


In 1996, the education system promulgated an overall reform program of the two types of sports courses. According to the program, the curriculum of physical education should include the course contents in the nine-year compulsory education syllabus for PE, compile a suitable "curriculum syllabus of the activity course" to make the activity class curriculum have local characteristics, and further elaborating the most unified athletics class curriculum syllabus. These two types of sports courses should take improvement of the physical quality of all students as the teaching goal, focus on training students' physical ability and health education, and link PE with the extracurricular physical education, in order to establish a reasonable structure of PE curriculum (Zhao \& Wang, 2011; Wang, 1998; Zhang \& Wang, 2008).

\subsection{Focus on Quality}

The aim of physical education teaching is to improve students' physical quality. In order to achieve this goal, the key lies in the contents and methods of curriculum implementation, so that they can satisfy the personalized and psychological needs of all students. PE teacher should strengthen the theoretical study, obtain the advanced modern PE theory and the psychological theory, and use these theories flexibly in the teaching practice. PE teachers should make students understand the importance of sports through their own teaching, gradually enhance their consciousness of physical education and improve their physical quality.

\section{Inheriting Excellent Sports Culture and Innovating the Theoretical System of Traditional Chi- nese Sports}

In the course of developing PE teaching theory, it is also very important to inherit and carry forward the national traditional sports.

\subsection{Efforts to Help Students to Build National Pride}

First of all, in PE teaching, teachers should let students understand the traditional sports culture of our country and the relationship between modern sports culture and traditional sports culture, and we should inherit excellent traditional sports culture and develop modern sports culture vigorously. Secondly, teachers should indoctrinate an important thought to the students in the class that, learning and inheriting excellent traditional sports culture is an important way to improve their cultural quality. Thirdly, teachers should help the students to establish a healthy view of sports culture and cultivate their patriotism emotion and national pride.

\subsection{Efforts to Show the National Characteristics in Sports Materials}

According to the national characteristics of different regions and the characteristics of various schools, some traditional sports items with national characteristics are included in the category of physical education.

\subsection{Try to Go Out and Realize Cooperation and Communication}

There are many national traditional sports projects in China, but they are mostly confined to the region without very good promotion and popularization. In recent years, the television media has made certain propaganda to the traditional sports project, and the national minority sports games are also held every four years, but many outstanding traditional sports projects have not been able to be promoted. Therefore, as for the realization of the traditional sports cooperation and exchange, especially in turning the school physical education into the national sports projects, the inheritance and development of national sports culture are very meaningful. 


\section{Deepening the Research on Theoretical System and Promoting the Development of Chinese Sports Teaching Theory into the Profound Culture}

\subsection{The Study of Physical Education Should Strengthen Democracy}

The guiding principle of the research on physical education in China is to "blossom, to have a school of contention", to be realistic and to create a democratic research atmosphere in the course of research. For example, sports experts launched an unusually enthusiastic discussion around Japan's "Happy Sports Theory" and "Sports Culture theory" in 1998, with a very strong democratic academic atmosphere.

\subsection{The Theory of Physical Education Should Be Strengthened}

The study of physical education in China is mainly about physical education, such as physical activity in the classroom, teaching methods, exercise density and so on, these contents are in fact need to be carried out in-depth study, but at present in these aspects of research, we are still in a shallow analysis, because of the lack of guidance theory. Now the sports teaching research center has shifted from the past teaching method research to the sports education research. Therefore, we should strengthen the study of physical education teaching, and pay attention to the theory of physical education. In order to realize the reform and opening up, we must get involved in the deep theory and use the research results of the deep theory in the concrete teaching practice, so that we can popularize it better and further develop and perfect the theoretical research system of sports education in China.

\subsection{The Study of Physical Education Should Strengthen the Integration of Research Methods}

We should make more progress in the research of physical education, especially on some complex subjects, and it is very important to integrate the research methods properly. With the development of society, China has made great progress in the research methods, so it plays a great guiding role in the application of all kinds of scientific knowledge in the theory and practice of physical education. At present, it is very feasible and practical to strengthen the integration of other subjects in the research of PE teaching.

\section{Innovating Teaching Methods and Combining PE Teaching Theory with Health Education}

In the school education system, the health education is a very important part, and it is also an important content in PE teaching. Therefore, we must attach importance to the combination of physical education and health education when we use the theory of PE teaching.

The standardization of health education should be strengthened in PE teaching. The school physical education should be formally integrated into the health teaching, so as to become a part of the physical education. To really implement the sports teaching mode, a health education class shall be taken every two weeks. We should strengthen the management of health education, and integrate the health education course into the school P.E. teaching plan to standardize it.

Sports and health education can keep abreast. Schools at all levels should integrate the health education into the category of school education, carry out the health guidance for students, guide students to take part in physical exercise, and try to master all kinds of fitness knowledge so as to enhance students' physique and promote students' physical and mental health.

PE teachers should strive to improve their personal quality. They should not only have strong physical education quality, but also strengthen the quality of health teaching. In the teaching, on the one hand, efforts should be made to improve students ' awareness of sports, to help students develop good physical exercise habit, on the other hand, to promote students ' health awareness and help students develop good health habits. 
Along with the implementation of the new nine-year compulsory education outline, we should expand the experimental school of Physical Education and health teaching, and strengthen the function of health education.

\section{Conclusion}

In the 21st century, we need to adhere to the "people-oriented" teaching concept, with "health first" as the guiding idea in the in-depth study on physical education model. In order to meet the needs of the physical health of the contemporary students, we should intensify our efforts to carry out the sports teaching programs that can help the students to improve the level of sports skills, strengthen the college students' awareness of sports, enhance the interest of the contemporary college students, and strive for the idea of "lifelong sports". In a word, in PE teaching, the physical education should constantly improve its theoretical accomplishment, set up the new P.E. teaching idea adapting to the development of times, combine the teaching with extracurricular learning, strengthen the practice summary, work hard for the construction of the theory system of physical education in our country, and promote the reform of PE teaching.

\section{References}

Wang, C. H. (1998). Discussion on the Effect of the Teaching of Physical Education Theory on General Colleges and Universities. Sports Journal, 2, 11-14.

Zhang, P., \& Wang, S. (2008). An Analysis of How to Carry out the Teaching of the Elective Course of Aerobics in Colleges and Univers ities. Science and Technology Information (Scientific Research and Teaching), 14, 67-69.

Zhao, S., \& Wang, K. B. (2011) Analysis on the Current Problems of Physical Education Reform in Colleges and Universities. Sports, 4, 17-19.

Zhu, H. S. (2008). Research on the Reform of Teaching Material Contents of Public Sports Theory in Universities. Sports World (Academic Edition), 6, 35-37. 